\title{
Diagnosing Non-HFE Hereditary Hemochromatosis
}

\author{
Brian Park, MD \\ Thomas Jefferson University, brian.park@jefferson.edu \\ Naman Upadhyay, MD \\ Thomas Jefferson Univeristy, naman.upadhyay@jefferson.edu \\ Dina Halegoua-Demarzio, MD \\ Thomas Jefferson University, Dina.Halegoua-DeMarzio@jefferson.edu
}

Follow this and additional works at: https://jdc.jefferson.edu/tmf

Part of the Internal Medicine Commons

Let us know how access to this document benefits you

\author{
Recommended Citation \\ Park, MD, Brian; Upadhyay, MD, Naman; and Halegoua-Demarzio, MD, Dina (2020) "Diagnosing Non-HFE \\ Hereditary Hemochromatosis," The Medicine Forum: Vol. 21 , Article 5. \\ DOI: https://doi.org/10.29046/TMF.021.1.007 \\ Available at: https://jdc.jefferson.edu/tmf/vol21/iss1/5
}

This Article is brought to you for free and open access by the Jefferson Digital Commons. The Jefferson Digital Commons is a service of Thomas Jefferson University's Center for Teaching and Learning (CTL). The Commons is a showcase for Jefferson books and journals, peer-reviewed scholarly publications, unique historical collections from the University archives, and teaching tools. The Jefferson Digital Commons allows researchers and interested readers anywhere in the world to learn about and keep up to date with Jefferson scholarship. This article has been accepted for inclusion in The Medicine Forum by an authorized administrator of the Jefferson Digital Commons. For more information, please contact: JeffersonDigitalCommons@jefferson.edu. 


\title{
Diagnosing Non-HFE Hereditary Hemochromatosis
}

\author{
Brian Park, MD, Naman Upadhyay, MD, Dina Halegoua-Demarzio, MD
}

\begin{abstract}
Non-HFE hemochromatosis is a rare cause of end stage liver dysfunction that is characterized by excessive iron deposition in the liver. The vast majority of primary iron overload is due to well documented mutations of the HFE genetic locus, however, rare genetic cases not involving the HFE locus have been documented. Here we present the case of a 63-year-old female who developed liver failure due to non-HFE hemochromatosis. Secondary causes of iron overload were ruled out, and genetic testing was negative for primary HFE (C282Y and H63D) mutations. We discuss the clinical work up involved in making the diagnosis of non-HFE hemochromatosis and the treatment options.
\end{abstract}

Keywords: Non-HFE Hemochromatosis, primary hemochromatosis, iron overload, hereditary hemochromatosis

\section{INTRODUCTION}

Hereditary Hemochromatosis $(\mathrm{HH})$ is a disease characterized by increased intestinal absorption of iron and subsequent deposition in tissues. Hemochromatosis is a progressive disease that without therapeutic intervention can lead to iron accumulation in tissues leading to organ damage such as liver cirrhosis, diabetes, skin discoloration, and cardiomyopathy ${ }^{1}$.

Primary hemochromatosis due to the HFE gene is the most common identified genetic disorder in Caucasians of northern European descent with a prevalence of 1 in 200 individuals and accounting for $60-95 \%$ of European iron overload cases². In contrast, most cases of iron overload that do not involve the HFE gene are due to secondary hemosiderosis. However, there are rarely observed gene mutations that result in primary hemochromatosis collectively called non-HFE hemochromatosis ${ }^{3}$.

\section{CASE REPORT}

A 63-year-old Caucasian female presented for evaluation of abnormal bile duct appearance on ERCP after being diagnosed with gallstone pancreatitis, duodenal ulcers and gastritis at another hospital. Over the past several years she had noticed increasing fatigue, unintentional weight gain of 30 pounds, lower extremity and abdominal swelling. The patient recalls having jaundice at the age of
14 , and at age 28 she was told she had hepatitis although her hepatitis testing was negative. She has a history of psoriasis and vitiligo. Her family history is notable for liver disease of unknown etiology in her grandmother, gallbladder and thyroid disease in her mother, daughter with psoriasis, and son with type 1 diabetes mellitus.

She rarely drinks alcohol. She has taken an occasional Aleve for arthritic pains but had not taken any NSAIDs in two years. She does not smoke cigarettes or use illicit drugs. She worked at a large wholesale grocery as a door greeter.

Her physical exam was notable for prominent scleral icterus, diffuse jaundice, abdominal distension with dullness in flanks but no tenderness, 3+ pitting edema in bilateral lower extremities, chronic vitiligo of hands and chest, palmar erythema, asterixis with mild confusion, but no spider angiomas or malar rash.

Her labs were significant for iron overload with iron saturation of $95 \%$, elevated ferritin of $4400 \mathrm{ng} / \mathrm{mL}$, decreased transferrin to $138 \mathrm{mcg} / \mathrm{dL}$, and iron level elevated to $185 \mathrm{mcg} / \mathrm{dL}$. She had a macrocytic anemia with hemoglobin of $9.0 \mathrm{~g} / \mathrm{dL}, \mathrm{MCV} 108$ and normal B12 and folate.

Labs were negative for CMV, EBV, VZV, HAVAb, HBGAg, HBVAb, HCVAb, and HIV. Normal AFP (3.7 ng.mL), A1AT (14 mg/dL), TSH (3.4 ulU/mL), A1c 4.1, and low normal ceruloplasmin $(19 \mathrm{mg} / \mathrm{dL})$. Presenting MELD-Na score was 17 ( Cr 0.6, Bili 4.9, INR 1.5, Na 140).

Elevated IgG, but negative ANA and ASMA (ruling out AlH and PBC). Gene mutations for primary HFE (C282Y and H63D) were negative.

MRI (Figure 1) was consistent with primary hemochromatosis effecting the non-reticuloendothelial system (non-RES); involving the liver, but not the spleen or bone marrow. Additionally, on the dual-sequence MRI (Figure 2) there is a drop in signal intensity on the image with the longer echo time ${ }^{10}$.

Liver biopsy (Figure 3) demonstrated bridging fibrosis and focal nodularity, stage 3-4. Features of chronic hepatitis evidenced by mild lobular and portal inflammation. Iron stain showing 4+ hepatocellular iron deposit. No evidence of steatohepatitis. No evidence of portal edema or brisk ductular reaction to support biliary obstruction.

Despite treatment her condition progressed to ESLD and she was listed with successful liver transplantation. 


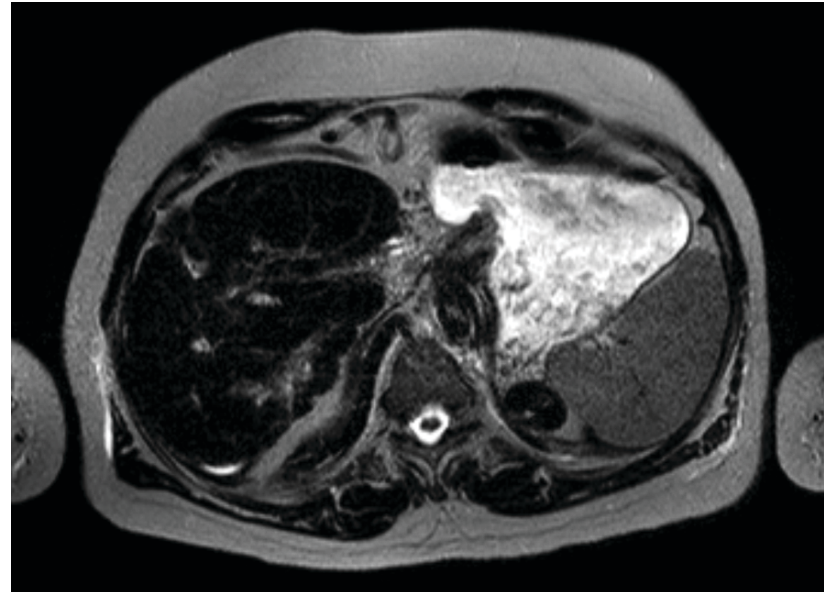

Figure 1: Figure 1: T2 weighted MRI showing decreased enhancement of the liver (darker appearance) but not the spleen, characteristic in iron overload due to primary hemochromatosis.

\section{DISCUSSION}

Hereditary Hemochromatosis $(H H)$ is a disease of iron overload that is most commonly due to mutations of the HFE gene. The HFE gene mutation most commonly involves a tyrosine for cysteine substitution at amino acid position 282, or protein product $C 282 Y^{1}$. The allele frequency of $\mathrm{C} 282 \mathrm{Y}$ is close to $5 \%$ in European populations according to the 1000 Genomes Project and explains the large number of European persons with primary hemochromatosis who are homozygous for C282Y HFE gene ${ }^{2}$

Rarely, there are cases of iron overload consistent with primary hemochromatosis that do not involve the HFE gene collectively called non-HFE hemochromatosis ${ }^{3}$. These non-HFE genes include hemojuvelin (HJV), hepcidin (HAMP), transferrin receptor (TFR2) and ferroportin (SLC4OA1). Though most known forms of primary hemochromatosis have recessive inheritance, SLC4OA1 is recognized as a rare autosomal dominant inherited genotype that can be associated with a splicing mutation4. These gene mutations have phenotypes that range from the severe juvenile forms of iron overload as in mutations of HJV and HAMP to the milder phenotypes associated with TFR2 and SLC4OA15. Typically, the earlier onset forms involve severe endocrine and cardiac manifestations that can result in death by the age of $30^{5}$. Notably, ferroportin mutations were first described in 1999 in individuals of Italian and Dutch descent, but were later observed in gene sequencing of Asian, American and African populations ${ }^{6,7}$.

The diagnosis of non-HFE hemochromatosis involves ruling out secondary causes of iron overload, quantifying liver iron stores via MRI or liver biopsy, determine the hereditary nature of the iron overload by genetic testing (typically for HFE only) $^{8}$. As mentioned previously, MRI

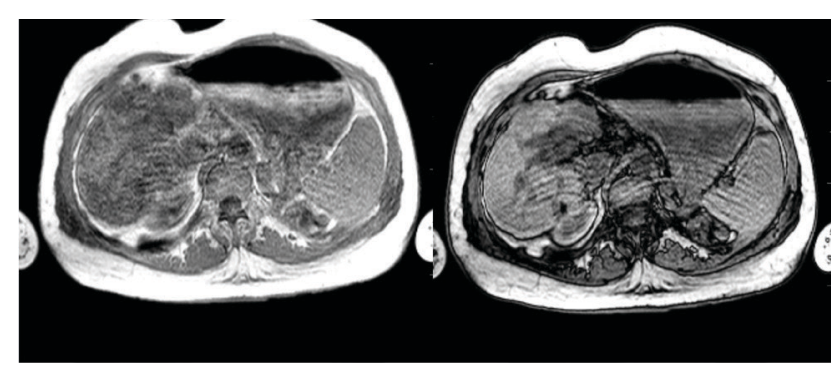

Figure 2: Dual sequence MRI "In Phase and Out of Phase" showing decreased signal of the liver on the "In Phase" image (left) compared to "Out of phase" image (right) which is consistent with hemochromatosis. The iron deposition is more severe in the liver.

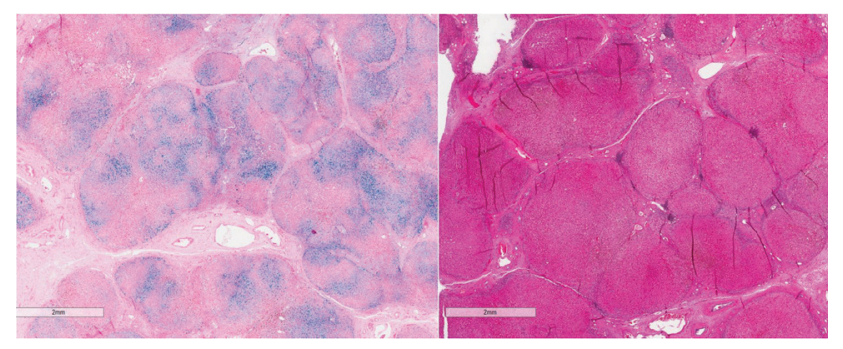

Figure 3: Iron stain from our patient showing 4+ hepatocellular iron deposition (left blue stain). H\&E stain demonstrated bridging fibrosis and focal nodularity, stage 3-4 (right pink stain) Features of chronic hepatitis evidenced by mild lobular and portal inflammation.

did not show involvement of spleen or bone marrow whereas for hemosiderosis or secondary hemochromatosis, iron deposition would be prominent in these locations.

Estimates of the prevalence of non-HFE hemochromatosis were previously about 10\% 6 . To date, 55 HJV cases, 13 HAMP cases, 49 TFR2 cases, and 60 cases of SLC4OA1 disease have been reported ${ }^{7}$. Next-generation sequencing supports the rarity of these non-HFE pathogenic alleles with predicted frequencies ranging from 0.00007 to 0.0004 . Compare this to the $5 \%$ allele frequency of the C282Y missense substitution as previously noted. Corresponding predicted frequencies of the genotypes range from 1 in 556 for SLC40A1 to 1 in 6,000,000 for TFR2 and as rare as 1 in 181,000,000 for HAMP?.

Heterozygous mutations in SLC40A1 lead to ferroportin disease and we were surprised to find relatively high frequencies of SLC40A1 variants classified as pathogenic. These variants were found at the highest frequencies among African populations (0.25\%) but were also present in the American (0.039\%), East Asian (0.033\%), and non-Finnish European (0.03\%) populations 7 . Non-HFE $\mathrm{HH}$ seems to be more prevalent in southern Europe compared with northern Europe.

Due to the lack of widely available direct gene sequencing, these non-HFE genes are not recommended to be tested unless investigating severe refractory cases ${ }^{8}$. 
Park, MD et al.: Diagnosing Non-HFE Hereditary Hemochromatosis

\section{REFERENCES}

1. Bacon BR, et al. Diagnosis and Management of Hemochromatosis: 2011 Practice Guideline by the American Association for the Study of Liver Diseases. Hepatology. 2011;54(1):328-343

2. Mcdonald CJ, et al. Iron Storage Disease in Asia-Pacific Populations: The Importance of Non-HFE mutations. Journal of Gastroenterology and Hepatology. 2013;28(7):1087-1094

3. Lok CY, et al. Iron Overload in the Asian Community. Blood. 2009;114(1):20-25

4. Zhang W, et al. Type 4B Hereditary Hemochromatosis Associated with a Novel Mutation in the SLC40A1 Gene. Medicine. 2017:96(38)

5. Pietrangelo A, et al. Non-HFE Hepatic Iron Overload. Seminars in Liver Disease. 2011;31(3): 302-318.

6. Washington K. Hepatic Iron Deposition: New Observations in Non-HFE Hemochromatosis. Advances in Anatomic Pathology. 2006;13(6):341-342.

7. Wallace DF, Subramaniam NV. The Global Prevalence of HFE and Non-HFE Hemochromatosis Estimated from Analysis of next-Generation Sequencing Data. Genetics in Medicine. 2015;18(6):618-626

8. Paulo CJDLS, et al. Non-HFE Hemochromatosis. Revista Brasileira De Hematologia e Hemoterapia. 2012;34(4):311-316.

9. Queiroz-Andrade M, et al. MR Imaging Findings of Iron Overload. RadioGraphics. 2009;29(6):1575-1589.

10. Merkle EM, Nelson RC. Dual Gradient-Echo In-Phase and Opposed-Phase Hepatic MR Imaging: A Useful Tool for Evaluating More Than Fatty Infiltration or Fatty Sparing. RadioGraphics. 2006;26(5):1409-1418. 